CUAJ honors its members and friends who have passed away. We invite colleagues of the deceased to submit brief remembrances. Please limit your notice to 200 words. Send your notice to journal@cua.org or fax it to $\mathbf{5 1 4 - 3 9 5 - 1 6 6 4}$
Cite as: Can Urol Assoc J 2021;15(2):70-1. http://dx.doi.org/10.5489/ cuaj.7141

\section{Denis Henry Hosking}

Canadian urology has lost a major leader of recent years with the passing of Dr. Denis Hosking.

Denis was born in Dundee, South Africa, attended schools in Pietermaritzburg, and after a year of military service in the South African Air Force, entered medical school at the University of Cape Town, graduating in 1972. While at medical school, he met Dianne (Dee) and they married in 1974. After working in hospitals in South Africa for three years, he and Dee moved to the U.K., where he underwent further surgical training and

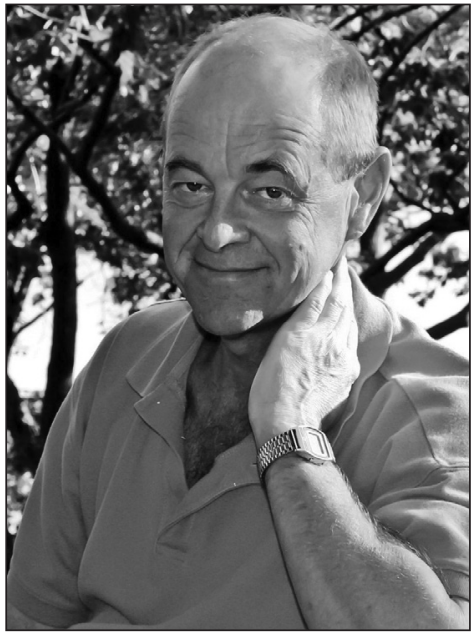
became a fellow of the Royal College of Surgeons of Edinburgh. The couple then moved to Winnipeg, where Denis accepted a position as a general surgery resident at the University of Manitoba.

Denis eventually transferred to the urology program, and then worked under the leadership of Ernie Ramsey, who became an important mentor. Denis achieved his FRCSC in 1982. After a further year of training in clinical urolithiasis at the Mayo Clinic-Rochester, he returned to Winnipeg to accept a position as an assistant professor of surgery in the Section of Urology. He remained a urologist at the Health Sciences Centre for the rest of his career.

In 1990, he was appointed head of the Section of Urology for the hospital and the university, positions he held until 2010. He was promoted to full professor of surgery in 1998. He held numerous positions in the department and faculty, primarily focusing on medical education and clinical service provision. It is fitting that the Department of Surgery at the University of Manitoba has established the Hosking award for the resident best exemplifying the CanMEDS roles.

Denis's academic achievements were focused on metabolic stone disease and surgery for renal stones. He coined the term "stone clinic effect" to describe the change in incidence of recurrent stone disease by just being seen in a dedicated stone clinic by a clinician skilled in managing these patients.

The 80 s was an exciting time to be a urologist. Denis was an active participant in the development and evolution of the technology used to treat stones, including percutaneous renal surgery, ureteroscopy, and intracorporeal lithotripsy. Winnipeg was one of the early Canadian centers to acquire extracorporeal shock wave lithotripsy. Frustrated by his dependence on radiologists to obtain access for percutaneous renal surgery and not having availability of the technology to permit antegrade access himself, Denis became skilled at and published on the retrograde approach. He is one of the few urologists to publish on his experience with ureteroscopic stone removal with sedation only. This demonstrates that not only did he have "gentle hands" as a surgeon, but clearly had a skilled team in the Urology Centre to achieve such success. Denis was particularly proud and recognized the importance of the team he built in Urology. He especially valued the support he received from the operating room 
staff, the nurses in the urology clinic and treatment areas, the radiology technicians, and the office staff. He considered every member of the team essential in providing the best possible patient care.

Beyond his clinical practice, Denis was a leader in Canadian urology. He was local organizing chair of the 1992 CUA annual meeting in Winnipeg, the only time the CUA has met in that city in 75 years. He was elected secretary of the CUA that same year and became noted for his accurately detailed, exhaustive minutes, recording every opinion of every member of the committee, even when those opinions changed during the discussions. He was president of the CUA in 1999-2000 and presided over the scientifically and socially successful meeting in Kelowna. Denis was an examiner for the Royal College in urology for many years and was chief examiner during the transition from the traditional two-part examination to the Comprehensive Objective Examination, which introduced the OSCE exam to urology. In 2008, he was awarded the CUA award for lifetime contributions to urology.

Denis enjoyed most sporting activities, although despite living in Winnipeg, never developed an appreciation for curling. He would try any sport, including skiing. Apart from the usual team sports played at school, he enjoyed tennis, squash, and developed a lifelong love of golf while still a schoolboy. He could be relied upon to participate in the annual golf tournaments at the CUA meetings. On one occasion, he won the tournament, and that was at the joint BAUS-CUA meeting in 1986 in London, U.K. In later years, Denis loved golf holidays down at Hilton Head Island.

Among his other interests, he enjoyed motorcycling and white-water kayaking. He twice completed the gruelling $120 \mathrm{~km}$ Dusi Canoe Marathon from Pietermaritzburg to Durban, South Africa. Outside of sports, he had great interest in photography and bridge.

Denis was committed to his adopted city and although growing up in a subtropical climate, where ice is only found in freezers or cold drinks, he never seriously contemplated living anywhere else. He was forever grateful for the opportunities he was given in Winnipeg and would relish describing the effects of the frigid sub-zero temperatures to anyone who had not personally experienced this degree of cold.

Those who knew him will remember him as a vibrant individual with an aura of mischief, a wicked sense of humor, and rapier sharp wit. He was not shy to be provocative and share his carefully considered opinions when he thought it necessary to stir up the session. His South African accent would thicken depending on the intensity of the discussion or the quantity of fluids that had been consumed. Colleagues and residents respected him as a gifted teacher, an outstanding leader, and a very thoughtful and skilled clinician. Most of all, he was a person of substance and integrity.

He faced the realities of his myeloma diagnosis in 2009 with dignity, courage, and forbearance. The last years were challenging but never did he complain about his plight.

He is survived by Dee, his children Nolan and Michelle (Paul Van Caeseele), and grand-children Luke, Mark, and Eric. He will be missed by his many colleagues, former residents, and friends across Canada and around the world. 